\title{
Relationship of the Location of the Ventricular Catheter Tip and Function of the Ventriculoperitoneal Shunt
}

\author{
Arman $\mathrm{DM}^{1}$, Ekramullah $\mathrm{SM}^{2}$, Mukherjee $\mathrm{SK}^{3}$, Joynul $\mathrm{I}^{4}$, Rashid $\mathrm{MH}^{5}$, Salam $\mathrm{MA}^{6}$, Quddus $\mathrm{MA}^{7}$, \\ Saifuddin AZM $^{8}$, Arefin MS $^{9}$
}

Conflict of interest: There is no conflict of interest relevant to this paper to disclose.

Funding Agency: Was not funded by any institute or any group.

Contribution of Authors: Arman DM was Principal investigator.

Ekramullah SM help for protocol preparation,

Mukherjee SK, Joynul I, Rashid MH, Salam MA, Quddus MA, Saifuddin AZM help for data collection and Arefin MS help for editorial formatting.

Copyright: @2019 Bang. JNS published by BSNS. This article is published under the creative commons CC-BY-NC license.

This license permits use distribution (https://creativecommons.orgf/ licences/by-nc/4-0/) reproduction in any medium, provided the original work is properly cited, and is not used for commercial purposes.

Received: 7 February, 2019

Accepted: 22 February, 2019

\begin{abstract}
Object: The objective of this study was to determine the relationship of the location of the ventricular catheter tip and function of the ventriculoperitoneal shunt.

Methods: This prospective observational study included 140 patients from a single institution who underwent a ventriculoperitoneal shunt procedure in which a new ventricular catheter was placed between September, 2013 and September 2016. Data abstracted for each patient included age, sex, diagnosis, site and side of ventricular catheter placement. Postoperative CT scan images were reviewed for accuracy of ventricular catheter placement. Patients were followed up over $21 / 2$ to $41 / 2$ years. 63 patients were available for follow up. We lost communication with rest of the patients. The relationship of the location of the ventricular catheter tip and function of the ventriculoperitoneal shunt was analyzed in 63 patients.
\end{abstract}

Results: There were 140 patients included in the study; accuracy ventricular catheter tip placement were 55 (39.28\%) using freehand technique. VP shunt functioned well in 43 (68.25\%) of 63 patients. Among the 43 patients with well functioning shunt, 19 were in accurate group, 7 were in suboptimal group and 17 were in inaccurate group. 26 patients (41.27\%) had good outcome with normal development and normal IQ

Conclusions: Mechanical malfunction and infection are the most significant problems associated with shunts for the treatment of hydrocephalus. Above all, a significant proportion of shunt failure was due to obstruction of the ventricular catheter, and accurate placement of the shunt catheter is highly important to reduce the incidence of shunt malfunction.

Key words: - Hydrocephalus - ventriculoperitoneal shunt $\cdot$ ventricular catheter placement $\cdot$ Accuracy $\bullet$ Function of VP Shunt.

Bang. J Neurosurgery 2019; 9(1): 16-21

\section{Introduction:}

Ventriculoperitoneal shunt placement is one of the most commonly performed neurosurgical procedures and it is a standard surgical procedure for hydrocephalus.
Despite advances in shunt catheter materials and the valves used, there remains a high rate of shunt failure. Approximately $30 \%$ to $50 \%$ of shunt surgeries for hydrocephalus require shunt revision within the first

1. Dr. D.M. Arman, Assistant Professor, Clinical Neurosurgery, National Institute of Neurosciences and Hospital, Dhaka, Bangladesh.

2. Prof. Dr. Sheikh Muhammad Ekramullah, Professor and Head, Paediatric Neurosurgery, National Institute of Neurosciences and Hospital, Dhaka, Bangladesh.

3. Dr. Sudipta Kumer Mukherjee, Assistant Prof. Paediatric Neurosurgery, National Institute of Neurosciences and Hospital, Dhaka, Bangladesh.

4. Dr. Joynul Islam, Associate Prof., Clinical Neurosurgery, National Institute of Neurosciences and Hospital, Dhaka, Bangladesh.

5. Prof. Dr. Mirza Hafizur Rashid, Clinical Neurosurgery, National Institute of Neurosciences and Hospital, Dhaka, Bangladesh.

6. Dr. M A Salam, Associate Prof., Neurotrauma, National Institute of Neurosciences and Hospital,Dhaka,Bangladesh.

7. Dr. M A Quddus Mia, Assistant Prof., Neuroanaesthesia, National Institute of Neurosciences and Hospital, Dhaka, Bangladesh.

8. Dr. AZM Saifuddin, Assistant Prof. Neuroanaesthesia, National Institute of Neurosciences and Hospital, Dhaka, Bangladesh.

9. Dr. Muhammad Shamsul Arefin, Consultant, Neuroanaesthesia, National Institute of Neurosciences and Hospital, Dhaka, Bangladesh.

Address of Correspondence: Dr. D.M. Arman, Assistant Prof. ,Department of Clinical Neurosurgery, National institute of Neurosciences, Dhaka, Bangladesh, email: armandmdr@yahoo.com, Cell-01745771780 
12 months. ${ }^{1}$ Mechanical dysfunction remains the most common cause of this failure. ${ }^{2}$ The most common reason for proximal catheter failure is believed to be obstruction of the catheter by the choroid plexus. ${ }^{3}$ and by debris from choroid plexus and ependymal. Optimal catheter placement should help reduce this risk, everything should be done to optimize catheter placement. Correct placement the catheter tip is essential for long term VP shunt function. Most ventricular catheters are placed using anatomical landmarks in a freehand fashion, although adjuncts are available, including stereotactic neuronavigation and intraoperative ultrasonography. In this study, we sought to determine the accuracy of ventricular catheter placement using anatomical landmark-guided freehand placement.

Correct placement of the cather tip is essential for long term VP shunt function.In a prospective observational study of 140 patients who underwent freehand catheter placement, postoperative CT scan images were reviewed for accuracy of ventricular catheter placement. This study evaluated the correlation of the location of the ventricular catheter tip and long term function of the VP shunt.

Multiple studies have concluded that ventricular catheters placed into the frontal horn or trigone, away from the choroid plexus and ventricular walls, result in a significant improvement in shunt survival. ${ }^{4}$ If reliable surgical techniques for accurate placement of ventricular catheters can be developed, shunt survival may improve. Conventional shunt insertion techniques rely on anatomical landmarks to determine catheter trajectory into the ventricle. The depth of catheter insertion is determined by a variety of methods including preoperative imaging, endoscopy, and the flow of CSF from the catheter. These techniques result in favorable catheter placement in approximately onethird to two-thirds of cases. ${ }^{5,6,7,8,9,10}$ The target was defined as the ipsilateral frontal horn or trigone.

Proximal catheter obstruction is known to be the most common cause of malfunctioning of ventriculoperitoneal (VP) shunt followed by infection. Thus, the chief concern when inserting a VP shunt should be the precise placement of the ventricular catheter. The standard technique of ventricular catheter placement depends on anatomic landmarks; however, this may not be satisfactory to consistently ensure optimal positioning of the ventricular catheter. The optimal position of the catheter tip was focused to reduce potential occlusion of proximal catheter by ventricular parenchyma or choroidal tissues. ${ }^{2}$ Many studies including Tuli et al.have shown that a ventricular catheter tip surrounded by cerebrospinal fluid (CSF) could decrease the risk of shunt failure. ${ }^{11}$

\section{Methods:}

\section{Study Design}

Authors conducted a prospective, obserbational single center study of paediatric hydrocephalus patients (< 18 years) undergoing first time ventriculoperitoneal shunt placement for hydrocephalus, between september 2013 and September 2016.All the patients of CT proven Hydrocephalus who have been managed prospectively in paediatric neurosurgery department, National Institute of Neurosciences and Hospital, Dhaka, Bangladesh were included in study. Each patient had a precise chart review with multiple variables including age, sex, causes of hydrocephalus. All patients had postoperative brain CT scan imaging to reveal the accuracy of shunt placement.

The primary outcome was location of the ventricular catheter on the first postoperative imaging study .Patients were followed up over $2 \frac{1}{2}$ to $4 \frac{1}{2}$ years.63 patients were available for follow up. We lost communication with rest of the patients. The relationship of the location of the ventricular catheter tip and function of the ventriculoperitoneal shunt was analyzed in 63 patients.

\section{Eligibility}

Participating pediatric neurosurgeons were required to target the ipsilateral frontal horn for all ventricular catheter placements.

All study patients met the following inclusion criteria:

1) Clinical and radiographic evidence of hydrocephalus as determined by a pediatric neurosurgeons that requires a ventriculoperitoneal shunt .

2) No prior history of shunt insertion or endoscopic third ventriculostomy for hydrocephalus .

3) Younger than 18 years of age at the time of shunt insertion.

Any of the following characteristics resulted in exclusion from the study:

1) Active CSF or abdominal infection. Acute phase of bacterial and tubercular meningitis presenting as hydrocephalus were excluded from study.

2) Loculations within the ventricular system. 
3) Hydranencephaly, alobar holoprosencephaly, or any other congenital anomaly of the brain that severely distorts the ventricular anatomy such that ventricular catheter location cannot be determined.

4) Other difficulties that would preclude follow-up at 1 year (for example, terminal illness with life expectancy $<1$ year).

\section{Data Collection}

From this population of patients, the following data were abstracted: age, sex, etiology of hydrocephalus, site of shunt (frontal or occipital), side of shunt (right or left), and accuracy of ventricular catheter placement (based on postoperative CT scan). An "accurate" ventricular catheter placement was credited when the tip of the ventricular catheter resided within the intended ventricle. All catheter placements in this study were intended for the ipsilateral ventricle. Accurate target is frontal horn, anterior to foramen of Monro; body,atrium and third ventricle also acceptable. Placement was considered inaccurate if the ventricular catheter tip resided in the contralateral ventricle, outside of the ventricular system in the parenchyma. The accuracy of each ventricular catheter placement was determined by documented tip position in each of the radiology reports from the postoperative CT scans. Each postoperative CT scan was then reviewed by a member of the study team to confirm that our assessment of the catheter tip agreed with the assessment documented in the radiology report. In all patients, the assessment of the study team was in accordance with the radiology report. The primary outcome was the location of the ventricular catheter tip on the first postoperative scan (CT scan)). The ventricular catheter tip was defined as the proximal $2 \mathrm{~cm}$ of the catheter (the hole-bearing segment). Patients were followed up over $2 \frac{1}{2}$ to $4 \frac{1}{2}$ years. 63 patients were available for follow up. The relationship of the location of the ventricular catheter tip and function of the ventriculoperitoneal shunt was analyzed in 63 patients. Function of VP shunt was assessed clinically.

\section{Results:}

A total of 140 first time VP shunt insertions were performed at NINS paediatric neurosurgery department .All patients underwent follow-up CT scan imaging to determine ventricular catheter location .

Baseline characteristics of the patient population are listed in Table 1 and 2. Most patients were neonates and infants at surgery.Mean age of all patients was $2.39 \mathrm{yrs}$ and range 6 days -13 yrs.52.86\% (74) patients were under 6 months and $67.14 \%$ (94) patients were under 1 year at surgery.

Side :

Right - 137 ( 97.86\%)

Left -3 ( $2.14 \%)$

Location of burr hole :

frontal - 1

occipital - 139

Table-I

Age of patients undergoing placement of VP shunt during the study period

\begin{tabular}{lcc}
\hline Age group & Number of patients & Percentage \\
\hline $0-1$ month & 13 & $9.28 \%$ \\
$1-6$ months & 61 & $43.57 \%$ \\
$6-12$ months & 20 & $14.28 \%$ \\
$1-2$ years & 13 & $9.28 \%$ \\
$2-3$ yrs & 8 & $5.71 \%$ \\
$3-13$ yrs & 25 & $17.85 \%$ \\
\hline
\end{tabular}

Female children were predominant. $47.15 \%$ were male and female were $52.85 \%$.

Table-II

Sex distribution of paeditric patient with Hydrocephalus.

\begin{tabular}{lcc}
\hline Sex & Number of patients & Percentage \\
\hline Male & 66 & $47.15 \%$ \\
Female & 74 & $52.85 \%$ \\
\hline
\end{tabular}

The most common causes of hydrocephalus were congenital aqueductal stenosis (60 [42.86\%] of 140), posterior fossa tumour ( $19\{13.57 \%]$ of 140 ), post meningitis Hydrocephalus (18[12.85] of 140) and myelomeningocele (19[13.57\%] of 140). Most of the hydrocephalus were obstructive $(112[80 \%])$. Communicating hydrocephalus were $18(12.85 \%)$.

Table-III Aetiology of Hydrocephalus

\begin{tabular}{lcc}
\hline $\begin{array}{l}\text { Cause of } \\
\text { Hydrocephalus }\end{array}$ & $\begin{array}{c}\text { Number of } \\
\text { patients }\end{array}$ & Percentage \\
\hline $\begin{array}{l}\text { Congenital Hydrocephalus/ } \\
\text { aqueductal stenosis }\end{array}$ & 60 & $42.86 \%$ \\
Post meningitis Hydrocephalus & 18 & $12.85 \%$ \\
Myelomeningocele & 19 & $13.57 \%$ \\
Posterior fossa Tumour & 20 & $14.28 \%$ \\
Supratentorial tumour & 11 & $7.85 \%$ \\
Dandy walker malfomation & 9 & $6.42 \%$ \\
Occipital encephalocele & 2 & $1.42 \%$ \\
Arachnoid cyst & 1 & $0.71 \%$ \\
\hline
\end{tabular}

On first postoperative CT scan image 55 (39.28\%) ventricular catheter tip resided in frontal horn,18 
(12.85\%) ventricular catheter tip resided in body, 12 $(8.57 \%)$ ventricular catheter tip resided in trigone, $(10.71 \%)$ ventricular catheter tip resided in $3^{\text {rd }}$ ventricle, $15(10.71 \%)$ ventricular catheter tip resided in brain parenchyma and $39(27.86 \%)$ ventricular catheter tip crossed the midline.

Table-IV

Overall ventricular catheter location on first postoperative CT scan image

\begin{tabular}{lcc}
\hline Frontal horn & 55 & $39.28 \%$ \\
body & 18 & $12.85 \%$ \\
trigone & 12 & $8.57 \%$ \\
3rd ventricle & 1 & $0.71 \%$ \\
brain parenchyma & 15 & $10.71 \%$ \\
tip crosses midline & 39 & $27.86 \%$ \\
\hline
\end{tabular}

140 ventricular catheters were freehand passed based on standard surface anatomy. $55(39.28 \%)$ of 140 freehand passed catheters were placed accurately. (Table 4,5) Ventricular catheter tip placement in body of lateral ventricle, trigone and $3^{\text {rd }}$ ventricle were considered suboptimal and acceptable.(31[22.14\%] Ventricular catheter tip placement in brain parenchyma and contralateral side were considered inaccurate. In our study $54(38.57 \%)$ ventricular tip placement were inaccurate.

Table-V

Freehand ventricular catheter placement

\begin{tabular}{lcc}
\hline Freehand Placement & $\begin{array}{c}\text { Number of } \\
\text { patients }\end{array}$ & Percentage \\
\hline Accurate & 55 & $39.28 \%$ \\
Suboptimal & 31 & $22.14 \%$ \\
Inaccurate & 54 & $38.57 \%$ \\
\hline
\end{tabular}

Correlation between ventricular catheter tip location and function of VP shunt :

Patients were followed up over $2 \frac{1}{2}$ to $4 \frac{1}{2}$ years.63 patients were available for follow up. We lost communication with rest of the patients. The relationship of the location of the ventricular catheter tip and function of the ventriculoperitoneal shunt was analyzed in 63 patients.

Table 6 showed the number patients according to cathter tip location and VP shunt function.VP shunt function was well maintained in 43 patients $(68.25 \%)$ of whom 19 were in accurate group, 7 were in suboptimal group and 17 were in inaccurate group demonstrating an odds ratio(OR) of $1.86(p<0.05)$. Two patients developed shunt malfunction, one were in suboptimal group and 1 were in inaccurate group, underwent revision surgery later. 19 patients $(30.16 \%)$ died during follow up period, among them 8 patients $(12.70 \%)$ were brain tumour (Craniopharyngioma -5 , Post. fossa tumour-3). In the rest 11 patients (17.46\%), 5 were in in suboptimal group and 6 were in inaccurate group. No patient without brain tumour died in accurate group.

Table 8 showed complications during postoperative follow up period. 10 patient developed walking difficulties, unsteady gait. 6 Patients with myelomeningocele persisted lower limb weakness and urinary incontinence. VP shunt infection was development in 2 patients (3.17\%). Chronic subdural hematoma was developed in one patient. One patient developed trasanal migration of shunt. 5 patients developed occasional seizure. 3 patients had gross developmental delay.

Table-VI

Location of a ventricular catheter tip and VP shunt function

\begin{tabular}{lccccc}
\hline Group & $\begin{array}{c}\text { Well } \\
\text { functioning } \\
\text { VP shunt }\end{array}$ & $\begin{array}{c}\text { VP shunt } \\
\text { malfunction }\end{array}$ & Revision & $\begin{array}{c}\text { Death } \\
\text { (Hydrocephalus } \\
\text { Without brain } \\
\text { tumour) }\end{array}$ & $\begin{array}{c}\text { Death } \\
\text { (Hydrocephalus } \\
\text { With brain } \\
\text { tumour) }\end{array}$ \\
\hline Accurate & 19 & 0 & 0 & 0 & 6 \\
Suboptimal & 7 & 1 & 1 & 5 & 1 \\
Inaccurate & 17 & 1 & 1 & 6 & 1 \\
Total & $43(68.25 \%)$ & 2 & 2 & $11(17.46 \%)$ & 8 (Craniopharyngioma -5, \\
Post. fossa tumour-3)
\end{tabular}


Table-VII

Comparison between numbers of patient with VP shunts in each location according to shunt function.

\begin{tabular}{lcc}
\hline Shunt location & \multicolumn{2}{c}{$\begin{array}{l}\text { Well functioning shunt } \\
(\mathrm{OR}=1.86, \mathrm{p}<0.05)\end{array}$} \\
& Yes & No \\
\hline $\begin{array}{l}\text { Accurate } \\
\begin{array}{l}\text { Sub optimal and } \\
\text { Inaccurate }\end{array}\end{array}$ & 19 & 6 \\
\hline
\end{tabular}

Table-VIII

Complications of VP shunt

\begin{tabular}{lc}
\hline Complications & Number of patients \\
\hline Walking difficulty & 10 \\
Seizure & 5 \\
Developmental delay & 3 \\
Shunt malfunction & 2 \\
Shunt Infection & 2 \\
Chronic subdural haematoma & 1 \\
Trans anal migration of VP shunt & 1 \\
\hline
\end{tabular}

26 patients $(41.27 \%)$ had good outcome with normal development and normal IQ.

\section{Discussion:}

Cerebrospinal fluid diversion using VP shunt placement is one of the most commonly performed neurosurgical procedures and one that carries a significant risk of failure requiring revision. Only $39.28 \%$ of catheters placed using the freehand technique were accurately placed in our study. The relationship of the location of the ventricular catheter tip and function of the ventriculoperitoneal shunt was analyzed in 63 patients. VP shunt function was well maintained in 43 patients $(68.25 \%)$ of whom 19 were in accurate group, 7 were in suboptimal group and 17 were in inaccurate group. Surprisingly VP shunt function was maintained well in 17 patients of inaccurate location, most of the ventricular catheter tips crossed midline and resided in contralateral frontal horn and lateral ventricle. In these cases VP shunts were functioned well because of ventricular catheter tip was surrounded by cerebrospinal fluid (CSF). Many studies including Tuli et al.have shown that a ventricular catheter tip surrounded by cerebrospinal fluid (CSF) could decrease the risk of shunt failure. ${ }^{11}$

In this study, two patients developed shunt malfunction, one were in suboptimal group and 1 were in inaccurate group, underwent revision surgery later.
19 patients died during follow up period, among them 8 patients were brain tumour (Craniopharyngioma -5 , Post. fossa tumour-3). In rest 11 patients 5 were in in suboptimal group and 6 were in inaccurate group. No patient without brain tumour died in accurate group. Death rate was more in inaccurate and suboptimal group of patients without brain tumour. In this study, death rate was very high and rate of revision surgery was low. All death occurred during postoperative period outside our hospital, they did not come in appropriate time to correct shunt malfunction. 8 patients $(12.70 \%)$ died due to brain tumour (Craniopharyngioma -5, Post. fossa tumour-3) related complication, one patient died from pneumonia and another one patient died from Diarrhoea. The incidence of shunt malfunction in patient with hydrocephalus (with out brain tumour) was nil, when tip was placed in accurate location and statistically significant difference was identified. The prevalence of shunt malfunction was also low when the tip was located in contralateral frontal horn and body of lateral ventricle of both side and surrounded by CSF.

26 patients $(41.27 \%)$ had good outcome with normal development and normal IQ .

Yamada et al reported that the incidence of shunt malfunction was very low when the ventricular catheter tip was placed in ipsilateral frontal horn. ${ }^{1}$

Previous data suggest that almost one third of adult patients undergoing CSF shunting will require revision. ${ }^{12}$ Optimal catheter placement may help reduce the risk of shunt failure. Ultrasonic and stereotactic guidance significantly improve the accuracy of ventricular catheter placement in comparison with freehand placement using surface anatomical landmarks.

The only factor identified in this study to be a risk factor for inaccurate placement was use of the freehand technique using standard anatomical landmarks. Among the freehand catheter placements, none of the factors identified in this study increased the risk of inaccurate placement. It is not surprising that the side of placement was not significant, but notably neither the location nor ventricular size. We found that placement is equally as likely to be inaccurate throughout the full range of ventricular size. While a $38.57 \%$ rate of inaccurate placement with the freehand technique appears to be exceptionally high, it is consistent with other published data. 
Wilson $\mathrm{T} J$ et al. reported that $55 \%$ of catheters were placed accurately in their study. ${ }^{13}$ Yamada SM et al. found that $42.9 \%$ of catheters were placed accurately in their study. ${ }^{1}$ Janson CG et al. published that $43.9 \%$ of catheters were placed accurately in their study. ${ }^{14}$ Whitehead WE et al. found that $49 \%$ of catheters were placed accurately in their study. ${ }^{4}$

Theodosopoulos et al. found that only $38 \%$ of catheters were optimally placed. Similarly, Lind et al. found that $56 \%$ of catheters were placed accurately in their study. ${ }^{13}$

Our data, together with theirs, suggest that we likely underestimate the rate of catheter misplacement using the freehand technique. Ultimately, more accurate placement only matters if it leads to reduced failure rates. Previous data from the pediatric literature suggest that utilizing an endoscope to ensure accurate placement of the ventricular catheter leads to reduced proximal failure but does not decrease the overall rate of shunt failure. ${ }^{10}$ Based on that data, we hypothesized that increased utilization of stereotactic neuronavigation and ultrasonic guidance with resultant increases in accuracy of placement would lead to reduced proximal catheter failure. Although image guidance offers a promising solution to lower the risk of inaccurate catheter placement, our review demonstrated that there is not yet a clear benefit of these technologies. Furthermore, there is some data to suggest that the use of programmable valves reduces shunt failure/revision. ${ }^{13}$

Findings from this study illustrate the importance of optimal placement of a VP shunt. Ventricular catheter tip must be inside the ventricle and surrounded by CSF.

\section{Conclusions:}

Mechanical malfunction and infection are the most significant problems associated with VP shunts for the treatment of hydrocephalus. Above all, a significant proportion of shunt failure was due to obstruction of the ventricular catheter, and accurate placement of the shunt catheter is highly important to reduce the incidence of shunt malfunction. Though ipsilateral frontal horn is the ideal location for VP shunt catheter tip placement, tip in contralateral frontal horn and body of ipsilateral and contralateral lateral ventricle are acceptable locations where tip is surrounded by CSF.

\section{References:}

1. Yamada SM, Kitagawa R, Teramoto A: Relationship of the location of the ventricular catheter tip and function of the ventriculoperitoneal shunt. Journal of clinical Neuroscience $20: 99-101,2013$

2. Korinek AM, Fulla-Oller L, Boch AL, Golmard JL, Hadiji B, Puybasset L: Morbidity of ventricular cerebrospinal fluid shunt surgery in adults: an 8-year study. Neurosurgery 68: 985-995, 2011

3. Villavicencio AT, Leveque JC, McGirt MJ, Hopkins JS, Fuchs HE, George TM: Comparison of revision rates following endoscopically versus nonendoscopically placed ventricular shunt catheters. Surg Neurol 59:375-380, 2003

4. William E. Whitehead, jay Riva-Jambrin, john C. Wellons, Abhaya V. Kulkarni, Richard holubkov,Aanna Illner, W.Jjerry Oakes, et al: No significant improvement in the rate of accurate ventricular catheter location using ultrasoundguided CSF shunt insertion: a prospective, controlled study by the Hydrocephalus Clinical Research Network. J Neurosurg Pediatrics 12:565-574, 2013

5 Albright AL, Haines SJ, Taylor FH: Function of parietal and frontal shunts in childhood hydrocephalus. J Neurosurg 69: 883-886, 1988

6. Kestle JR, Drake JM, Cochrane DD, Milner R, Walker ML, $A b$ bott $R$ III, et al: Lack of benefit of endoscopic ventriculoperitoneal shunt insertion: a randomized controlled trial. J Neu rosurg 98:284-290, 2003

7. Lind CR, Tsai AM, Lind CJ, Law AJ: Ventricular catheter placement accuracy in non-stereotactic shunt surgery for hydrocephalus. J Clin Neurosci 16:918-920, 2009

8. Missori P, Artizzu S, Salvati M: Immediate postoperative CT to assess the correct positioning of a ventricular catheter. Br J Neu rosurg 14:44-45, 2000

9. ShkolnikA, McLone DG: Intraoperative real-time ultrasonic guidance of ventricular shunt placement in infants. Radiology 141:515-517, 1981

10. Wan KR, Toy JA, Wolfe R, Danks A: Factors affecting the accuracy of ventricular catheter placement. J Clin Neurosci 18:485-488, 2011

11. Janak Raj, "VKulwant Singh, "Divye Prakash Tiwari:Conventional Versus Neuro-Navigation Guided Shunt Surgery. World Journal of Medical Research Volume No 4,2013

12. Reddy GK, Bollam P, Shi R, Guthikonda B, Nanda A: Management of adult hydrocephalus with ventriculoperitoneal shunts: long-term single institution experience. Neurosurgery 69:774-781, 2011

13. Thomas J. Wilson, William R. Stetler JR., WaJD N.. Al-holou ,Stephen E. Sullivan: Comparison of the accuracy of ventricular catheter placement using freehand placement, ultrasonic guidance, and stereotactic neuronavigation. $J$ Neurosurg 119:66-70, 2013

14. Christopher G. Janson, Liudmila G. Romanova, KyLe D. Rudser, Stephen J. Haines: Improvement in clinical outcomes following optimal targeting of brain ventricular catheters with intraoperative imaging. J Neurosurg 120:684-696, 2014 